\title{
COPING STRATEGIES IN THE SOUTH AFRICAN POLICE SERVICE
}

\author{
J. PIENAAR \\ S. ROTHMANN \\ WorkWell: Research Unit for People, Policy and Performance, \\ Faculty of Economic \& Management Sciences \\ $P U$ for $C H E$
}

\begin{abstract}
The objective of this study was to determine the internal consistency, construct validity, structural equivalence and item bias of the COPE, and to determine the differences between coping strategies of various demographic groups in the South African Police Service. A cross-sectional survey design was used. A random, stratified sample $(N=1431)$ was taken of police members in eight South African provinces. The COPE and a biographical questionnaire were administered. Four internally consistent factors were extracted, namely Approach Coping, Avoidance, Seeking Emotional Support and Turning to Religion. These factors showed structural equivalence for police members of all race groups and no items were biased. Differences in coping strategies were found for different ranks and races.
\end{abstract}

\section{OPSOMMING}

Die doelstelling van hierdie studie was om die interne konsekwentheid, konstrukgeldigheid, strukturele ekwivalensie en itemsydigheid van die COPE-vraelys te bepaal en om verskille tussen die coping-strategieë van verskillende demografiese groepe in die Suid-Afrikaanse Polisiediens te bepaal. 'n Dwarssnee opname-ontwerp is gebruik. 'n Ewekansige gestratifiseerde steekproef $(N=1431)$ is van polisielede in agt provinsies van Suid-Afrika geneem. Die COPE en 'n biografiese vraelys is afgeneem. Vier intern konsekwente faktore, naamlik Benaderings-coping, Vermyding, Soeke na Emosionele Ondersteuning en Keer-na-Religie is onttrek. Hierdie faktore het strukturele ekwivalensie vir alle rassegroepe getoon en geen items was sydig nie. Verskille rakende coping-strategieë is vir verskillende rang en rasse gevind.

The level of stress an individual experiences in his or her organisational context, and the extent to which adverse effects such as psychological and other strains occur, depend on how effectively he or she copes with stressful organisational situations (Bhagat et al., 2001). Research supports the contention that the ways people cope with stress and daily living affect their psychological, physical and social well-being (Ben-Zur, 1999; Cohen \& Lazarus, 1979; Friedman \& Vandenbos, 1992; Greenglass, 1996; Violanti \& Paton, 1999).

Coping strategies represent the efforts, both behavioural and cognitive, that people invest in order to deal with stressful encounters (Lazarus \& Folkman, 1984). Coping has been differentially conceived in several ways (Livneh, Antonak \& Gerhardt, 2000): 1) both as personality trait and situationally determined response; 2) a dynamic process and a static construct; 3) a strategy, that is mature, adaptive and flexible, but also a reaction, that is neurotic, maladaptive and rigid; and 4) a global, generally dichotomous concept, but also an intricate, hierarchically structured, multilevel concept.

The most familiar and widespread coping taxonomy is the one proposed by Folkman and Lazarus (1980). These authors described coping as either problem-focused or emotion-focused. Parker and Endler (1992) demonstrated that these dimensions have been recovered in nine out of 13 studies. Problem-focused coping strategies aim at actively dealing with the problem. In contrast, emotion-focused coping is directed at dealing with the emotional distress that is evoked by the problem. Endler and Parker (1990) suggest that the third basic strategy that may be used in coping with stress is avoidance. Avoidance can include either person-oriented or task-oriented strategies. Avoidance differs from problem- and emotion-focused coping in that avoiding a situation actually removes the person from the stressful situation, whereas problem- and emotion-focused coping might help the person manage the stressful situation while he or she remains in it (Kowalski \& Crocker, 2001).

In the police stress literature, Evans, Coman, Stanley and Burrows (1993) define effective coping as (a) the efficacy with

Requests for copies should be addressed to: S Rothmann, WorkWell: Research Unit for People, Policy and Performance, Faculty of Economic \& Management Sciences, PU for CHE, Private Bag X6001, Potchefstroom, 2520 which individuals deal with their emotional responses to stressors and act to resolve the stressors, and (b) the cost of their effectiveness to individuals. The important issue is the extent to which police officers emphasize the use of one coping strategy over the other (Billings \& Moos, 1984; Headey \& Wearing, 1990; Hart, Wearing \& Headey, 1995).

Studies on coping of police members have conceptualised and measured coping strategies in various ways, but several significant patterns have emerged (Patterson, 1999). Maladaptive behaviours such as excessive alcohol intake, drug use, smoking and overeating have been found to be ineffective and maladaptive as coping strategies among the police (Burke, 1993; Dietrich \& Smith, 1984). It has also been stated that poor coping skills appear to be a significant factor in determining the intensity with which stress is experienced in police work (Anshel, 2000). The use of maladaptive coping skills in police work leads to the experience of chronic, long-term stress (Hurrel, 1995; Nordlicht, 1979), and often results in job burnout and police members leaving the profession (Burke \& Deszca, 1986; Malloy \& Mays, 1984).

Evans et al. (1993) showed that police officers tend to use more problem-focused coping strategies (aimed at changing stressful occupational events), and less emotion-focused coping strategies (aimed at regulating their distress). Violanti (1992) found that the use of emotion-focused coping strategies result in higher levels of psychological distress, while the use of problem-focused coping strategies resulted in lower levels of psychological distress. Police officers probably compound stress by avoiding emotion-focused strategies, and when using such strategies, it only acts to exacerbate psychological stress, because the expression of emotion is not allowed in the policing environment (Kop \& Euwema, 2001; Stephens \& Long, 2000).

The nature and context of a stressor, the range of coping responses available and the emotional reaction of individuals might also be influenced by the differing role that race and culture plays in their lives (Coyne \& Gottlieb, 1996; Slavin, Rainer, McCreary \& Gowda, 1991). Dominant cultural scripts concerning coping through self-reliance, support seeking and religiosity could have an effect on coping 
strategies. In this regard, some variability has been demonstrated due to subculture and ethnicity (Ball, Warheit, Vandiver \& Holzer, 1980).

Since most coping instruments were developed in White middle-class populations, they reflect the cultural values, cultural scripts and culture-specific response sets of this population, and might therefore not be as relevant for individuals from different cultures (Prelow, Tein, Roosa \& Wood, 2000). While the Coping Orientations to the Problems Experienced Questionnaire (COPE) (Carver, Scheier \& Weintraub, 1989) has been studied in a variety of international contexts, such as Italy (Sica, Novara, Dorz \& Sanavio, 1997), Croatia (Hudek-Knežević \& Kardum, 1996; Hudek-Kně̌evi ć, Kardum \& Vukmirovi, 1999; Kardum \& Hudek-Knežević, 1995) and Estonia (Kallasmaa \& Pulver, 2000), it has been shown that only seven of the COPE's subscales (Restraint Coping, Seeking Social Support for Emotional Reasons, Seeking Social Support for Instrumental Reasons, Acceptance, Denial, Focus On and Venting of Emotion and Humour) appear to have similar factor structures and are likely to measure the same underlying coping constructs in different cultural groups (Prelow et al., 2000). The Active Coping, Planning, Positive Reinterpretation and Growth, and Mental Disengagement subscales did not demonstrate item equivalence.

Little research has to date been done regarding the coping strategies used in the SAPS. The South African Police Service (SAPS) presents a unique environment to study coping strategies, both because the police force in question has to deal with one of the highest crime levels in the world (Nedcor Project, 1996), and members of the SAPS are seemingly not coping well, as reflected in reported rates of illness, post-traumatic stress, medical boarding, burnout, alcohol abuse, suicides, decreased levels of job satisfaction and job performance, and high levels of absenteeism and resignation (Anshel, 2000; Nel \& Burgers, 1998; Nel, 1994; Pretorius, 1998; Rothmann \& Agathagelou, 2000; Rothmann \& Strijdom, 2002).

South Africa is a multicultural society and the SAPS employs individuals of diverse cultural backgrounds. Within the South African context it cannot be taken for granted that scores obtained in one culture can be compared across cultural groups. Before comparing scores across cultural groups, equivalence and bias should be tested (Van de Vijver \& Leung, 1997). Without a test of equivalence and bias it is impossible to know to what extent scores or constructs underlying an instrument can be compared across cultures. Meaningful comparative studies of coping processes across populations can only be conducted when there are reasonable assurances that the instruments used in the study are equivalent across the populations (Hui \& Triandis, 1985; Knight \& Hill, 1998; Prelow et al., 2000).

Some authors regard the most notable feature in coping literature as the problems experienced with the psychometric properties of tools employed in coping research (Hardy, Jones \& Gould, 1996; Schwarzer \& Schwarzer, 1996). A central psychometric issue relates to the dimensions underlying coping inventories, because these dimensions operationalize coping as a conceptual scheme and thereby influence coping theory (Cook \& Heppner, 1997). For any psychometric measure of coping, the consistency and validity of its performance in measurement are thus of paramount importance. The objective of this study was to determine the construct validity, internal consistency, structural equivalence and item bias of the COPE in the SAPS and to examine differences in coping strategies of different ranks and race groups.

\section{Coping}

A more theoretical conceptualisation than the dichotomy of problem- and emotion-focused coping was developed at the end of the eighties by Carver et al. (1989). These authors developed an instrument for the measurement of coping that conceived it in terms of 14 different subscales. Since the origin of this instrument more than a decade ago, however, factor analyses of the items have resulted in varying underlying structures. Studies based on factor analyses produced taxonomies consisting of three (Ben-Zur, 1998; Bishop et al., 2001; Cook \& Heppner, 1997; Hudec-Kneeviæ et al., 1999; Ingledew, Hardy, Cooper \& Jemal, 1996; Kallasmaa \& Pulver, 2000; Laurent, Catanzaro \& Callan, 1997; Lyne \& Roger, 2000; Mitchell \& Hastings, 2001), four (Carver et al., 1989; Phelps \& Jarvis, 1994; Ferguson, 2001; Fortune, Richards, Griffiths \& Main, 2002; Ward \& Kennedy, 2001) and five (Finch, Panter \& Caskie, 1999; Sica et al., 1997) factors. Apart from finding different numbers of factors, factor structures also do not replicate consistently across studies.

When comparing subsequent factor analyses to the one originally reported by Carver et al. (1989), interesting results emerge. For one, the factors of task and cognitive coping originally produced have subsequently emerged as a single factor in various studies (Ingledew et al., 1996; Cook \& Heppner, 1997; Ferguson, 2001; Fortune et al., 2002; Hudek-Knežević et al., 1999). This combined factor has also been reproduced in other studies, with the extra scales of Seeking Social Support for Instrumental Reasons (Lyne \& Roger, 2000), and Turning to Religion (Laurent et al., 1997).

The emotion factor has been reproduced in subsequent factor analyses (Ben-Zur, 1998; Ferguson, 2001; Finch et al., 1999; Fortune et al., 2002; Hudec-Kneeviæ et al., 1999; Ingledew et al., 1996; Kallasmaa \& Pulver, 2000; Laurent et al., 1997; Sica et al., 1997), but also without Seeking Social Support for Instrumental Reasons (Phelps \& Jarvis, 1994) and without Focus On and Venting of Emotions (Cook \& Heppner, 1997; Ward \& Kennedy, 2001).

The avoidance factor has been reproduced with the scales originally proposed (Ferguson, 2001; Laurent et al., 1997), but also loads the subscales of Alcohol/Drug Disengagement (Cook \& Heppner, 1997; Finch et al., 1999; Hudek-Knežević et al., 1999; Phelps \& Jarvis, 1994; Sica et al., 1997), Turning to Religion (Hudek-Knežević et al., 1999), the Acceptance scale (Kallasmaa \& Pulver, 2000), Focus On and Venting of Emotions (Bishop et al., 2001; Ward \& Kennedy, 2001), as well as Positive Reinterpretation and Growth (Ward \& Kennedy, 2001).

Turning to Religion has come to the fore as a separate factor (Lyne \& Roger, 2000; Sica et al., 1997), but also with Positive Reinterpretation and Growth (Finch et al., 1999), Denial (Mitchell \& Hastings, 2001) and Humour (Fortune et al., 2002). According to Zeidner and Hammer (1992), spiritual resources help people to cope with stress primarily through the appraisal process, by providing a perceptual framework that can help establish the meaning of a stressor in a larger context and also help prescribe acceptable coping techniques. By looking at the other subscales typically loading with Turning to Religion, it might be postulated that this factor can be thought of as one primarily emerging in the attribution of meaning to stressful events. Denying, reinterpreting or laughing about a stressful event helps the individuals manage their reaction.

The above-mentioned results suggest a four-factor structure underlying the COPE Questionnaire. The first factor could be labelled approach coping, which includes either the three scales (Active Coping, Planning, Suppression of Competing Activities) as originally proposed, or an assortment of the added scales from the cognitive coping factor. The second factor could be labelled as social/emotional coping, which includes the three scales originally proposed (Seeking Social Support for Emotional Reasons, Seeking Social Support for Instrumental Reasons and Focus On and Venting of Emotion), and has been recognised as the most frequently reproduced 
(Kallasmaa \& Pulver, 2000). The third factor deals with avoidance coping and typically includes the three scales originally proposed (Denial, Behavioural Disengagement and Mental Disengagement), but Alcohol/Drug Disengagement has also loaded on this factor in six subsequent studies (Cook \& Heppner, 1997; Finch et al., 1999; Hudek-Kneeviæ et al., 1999; Mitchell \& Hastings, 2001; Phelps \& Jarvis, 1994; Sica et al., 1997). The fourth factor is made up by Turning to Religion and/or Humour, which might be such specific coping strategies that they cannot be defined as exclusively approach, social/emotional or avoidant, for they probably serve the purpose of all of these. It could also be a case of specificity regarding the function this coping strategy serves for the user.

According to Cox and Ferguson (1991) and Ferguson and Cox (1997), in addition to the conventional dichotomy of problemand emotion-focused coping, two other dimensions might be considered, one concerned with reappraisal and the other with avoidance. This literature review suggests religion and humour to serve the reappraisal function, perhaps by removing the person psychologically or physically, or even morally (as in the case of religion) from the problem. According to Kallasmaa and Pulver (2000), at least three secondary COPE factors are required for an adequate explanation of the variance in the data on coping studies.

Demographic factors such as race and gender have been emphasised as influential in coping responses (Coyne \& Downey, 1991, Kessler, Price \& Wortman, 1985), and in reported sources of work stress (Patterson, 2000), whereby coping is indirectly influenced. Furthermore, demographic factors have been shown to interact with age (Folkman, Lazarus, Pimley \& Novacek, 1987) and gender (Folkman \& Lazarus, 1980) to affect coping responses among individuals.

Recent South African research (Rothmann \& Strijdom, 2002; Rothmann \& Van Rensburg, 2001) examining coping in a policing context found police members to achieve the highest scores on Turning to Religion and Planning as coping strategies. It was noted as a concern that police members scored low on the venting of emotions. This tendency may be the result of emotional detachment due to the nature of their work and their lack of trust in the organisation (Rothmann, Sieberhagen \& Cilliers, 1998). It could be expected that police members will refuse to share their emotional reactions to job stressors with others, which may isolate them from social support at work as well as home (Evans \& Coman, 1992).

In both combat veterans and civilians, a positive relationship has been established between the severity of Post Traumatic Stress Disorder (PTSD) following combat and post-war stress and emotion-focused coping, and a negative relation with problemfocused coping (Nezu \& Carnevale, 1987; Solomon, Avitzur \& Mikulincer, 1989; Solomon, Mikulincer \& Avitzur, 1988; Zeidner \& Ben-Zur, 1994). In policing, well-being is affected by how individuals cope following exposure to stressful events (Violanti \& Paton, 1999).

Considering the major organisational changes faced by the SAPS in the form of employment equity and internal transformation, and the positive relation of problem-focused coping with both organisational change (Terry, Callan \& Sartori, 1996) and general work stress (Terry, Tonge \& Callan, 1995), the measurement of prevailing coping dispositions, and differences regarding these, are invaluable in maintaining worker health.

When measures are applied to different cultural groups, issues of measurement bias and equivalence become important (Van de Vijver \& Leung, 1997). According to Van de Vijver and Leung (1997), construct equivalence and bias of measuring instruments should be computed in each study that takes place in a multicultural or cross-cultural context. Construct equivalence indicates the extent to which the same construct is measured across all cultural groups studied. When an instrument measures different constructs in different cultures, no comparison can be made. The same construct is measured in the case of construct equivalence (also labelled structural equivalence). No studies of construct equivalence of the COPE have previously been done in South Africa.

Item bias should also be computed. An item is an unbiased measure of a theoretical construct, for example of coping, if persons from different cultural groups who use a certain strategy equally have the same average score on the item (Van de Vijver \& Leung, 1997). Persons with an equal standing on the theoretical construct underlying the instrument should have the same expected score on the item, irrespective of group membership. The definition of bias does not stipulate that the averages of cultural groups should be identical, but only that these averages should be identical across cultural groups for persons who use specific coping strategies equally. Item bias can be produced by sources such as incidental differences in appropriateness of the item content and inadequate item formulation. Bias will lower the equivalence of a measuring instrument. Two types of item bias are distinguished, namely uniform bias and nonuniform bias (Van de Vijver \& Leung, 1997). Uniform bias refers to influences of bias on scores that are more or less the same for all score levels. Nonuniform bias refers to influences that are not identical for all score levels.

\section{METHOD}

\section{Research design}

A survey design was used to achieve the research objectives. The specific design was the cross-sectional design (Shaughnessy \& Zechmeister, 1997).

\section{Sample}

Random samples $(N=1431)$ were taken from police stations in the Limpopo Province, Gauteng, Mpumalanga, Northern Cape, Western Cape, Eastern Cape, Natal and Free State. Stations were divided into large (more than 100 staff members), medium (25-100 staff members) and small (fewer than 25 staff members). Student and civilian members of the police were not included in this study. All functional police members at randomly identified small and medium stations in each of the provinces were asked to complete the questionnaire. At the large stations, stratified random samples were taken according to gender and race. Table 1 presents some of the characteristics of the participants.

\section{TABLE 1}

Characteristics OF THE STUdy POPUlation $(N=1431)$

\begin{tabular}{llr}
\hline Variable & Category & Percentage \\
\hline Race & White & 41,15 \\
& Black & 40,07 \\
& Coloured & 14,77 \\
& Indian & 4,01 \\
Rank & Constable & 7,69 \\
& Sergeant & 19,43 \\
& Inspector & 54,16 \\
& Captain & 15,58 \\
& Superintendent & 2,45 \\
& Senior Superintendent & 0,70 \\
Gender & Male & 81,90 \\
& Female & 18,10 \\
\hline
\end{tabular}


Table 1 shows that the sample consisted of almost equal parts Black and White participants, with Indian and Coloured people making up less than $19 \%$ of the total sample. The sample was predominantly made up of sergeants, inspectors and captains $(89,17 \%)$, with inspectors forming the largest component $(54,16 \%)$. Almost $60 \%$ of the sample $(58,35 \%)$ had Grade 12 qualifications. The sample contained mostly married officers.

\section{Measuring battery}

Two questionnaires were used in this research, namely the Coping Orientations to Problems Experience Questionnaire (COPE) (Carver et al., 1989), and a biographical questionnaire compiled by the researchers.

- The Coping Orientations to the Problems Experienced Questionnaire (COPE) (Carver et al., 1989) was designed to measure both situational and dispositional coping strategies. In the present study, the dispositional version consisting of 53 items was used. Response choices were from 1 (I usually don't do this at all) to 4 (I usually do this a lot). The COPE measures 14 coping strategies. In previous South African research, Storm and Rothmann (in press) found acceptable alpha values, with inter-item correlation coefficients varying between 0,25 (Acceptance) and 0,65 (Turning to Religion), showing acceptable levels of internal consistency for this questionnaire.

- A questionnaire was developed to gather information about the biographical characteristics of the participants, such as race, rank and gender.

Statistical analysis

The statistical analysis was carried out with the help of the SAS program (SAS Institute, 2000). To evaluate the construct validity of the COPE, Principal factors extraction with varimax rotation was performed through SAS FACTOR on 53 items of the COPE. Principal components extraction was used prior to principal factors extraction to estimate the number of factors, presence of outliers and factorability of the correlation matrices. The criterion for factors was an eigenvalue greater than or equal to one after varimax rotation. The scree plot was also employed.

Internal consistencies of the measuring instrument were assessed by Cronbach alpha coefficients and inter-item correlations (Clark \& Watson, 1995). Coefficient alpha conveys important information regarding the proportion of variance contained in a scale, while the mean inter-item correlation coefficient (which is a straightforward measure of internal consistency) is a useful index to supplement information supplied by coefficient alpha (Clark \& Watson, 1995). However, simply focusing on the mean inter-item correlation cannot ensure unidimensionality of a scale - it is necessary to examine the range and distribution of these correlations as well.

Construct (structural) equivalence was used to compare the factor structures of the COPE for different race groups. Exploratory factor analysis and target (Procrustean) rotation were used to determine construct equivalence (Van de Vijver \& Leung, 1997). According to Van de Vijver and Leung (1997), it is not acceptable to conduct factor analyses for different cultural groups to address the similarity of factor-analytical solutions because the spatial orientation of factors in factor analysis is arbitrary. Rather, prior to an evaluation of the agreement of factors in different cultural groups, the matrices of loadings should be rotated with regard to each other (i.e., target rotations should be carried out). The factor loadings of separate groups are rotated to a joint common matrix of factor loadings. After target rotation had been carried out, factorial agreement was estimated using Tucker's coefficient of agreement (Tucker's phi). This coefficient is insensitive to multiplications of the factor loadings, but is sensitive to a constant added to all loadings of a factor. The following formula is used to compute Tucker's phi: $p_{x y}=\frac{\sum x_{i} y_{i}}{\sqrt{\sum x_{i}^{2} y_{i}^{2}}}$

This index does not have a known sampling distribution; hence it is impossible to establish confidence intervals. Values higher than 0,95 are seen as evidence for factorial similarity, whereas values lower than 0,85 are taken to point to nonnegligible incongruities (Van de Vijver \& Leung, 1997). This index is sufficiently accurate to examine factorial similarity at a global level. However, if construct equivalence is not acceptable, bias analyses should be carried out to detect inappropriate items.

An extension of Cleary and Hilton's (1968) use of analysis of variance was applied to identify item bias (Van de Vijver \& Leung, 1997). Bias was examined for each item separately. The item score was the dependent variable, while race groups (four levels) and score levels were the independent variables. Score groups were composed on the basis of the total score on the COPE. A total of ten score levels were obtained by making use of percentiles identified through SAS UNIVARIATE. This made it possible to use score groups with at least 50 persons each. Two effects were tested through analysis of variance, namely the main effect of race, and the interaction of score level and race. When both the main effect of race and the interaction of score level and race are non-significant, the item is taken to be unbiased.

Descriptive statistics (means, standard deviations, skewness and kurtosis) and inferential statistics were also used to analyse the data. One-way analysis of variance (ANOVA) was used to determine differences between the sub-groups in the sample. Tukey Studentized Range tests were done to indicate which groups differed significantly when ANOVAS were done. The following formula was used to determine the practical significance of difference in means between two groups (Steyn, 1999):

$d=\frac{\operatorname{Mean}_{A}-\operatorname{Mean}_{B}}{\text { Root MSE }}$

where

Mean $_{\mathrm{A}}=$ Mean of the first group

Mean $_{\mathrm{B}}=$ Mean of the second group

Root MSE $=$ Root Mean Square Error

A cut-off point of 0,50 (medium effect, Cohen, 1988) was set for the practical significance of differences between means.

\section{RESULTS}

The 14 scales of the COPE were subjected to a confirmatory factor analysis and internal consistency analyses. However, because the current factor structures were not confirmed and many alpha coefficients were lower than the cut-off point of 0,70 (Nunnally \& Bernstein, 1994) it was decided to proceed with exploratory factor analysis.

The results of the exploratory factor analysis of the COPE items are shown in Table 2. Loadings of variables on factors, communalities and percent of variance and covariance are shown. Variables are ordered and grouped by size of loading to facilitate interpretation. Zeros represent loadings that were under 0,45 ( $20 \%$ of variance). Labels for each factor are suggested in a footnote.

Oblique rotation showed inter-factor correlations for Factors 1 and $3(r=0,44)$ and 1 and $4(r=0,41)$. The other inter-factor correlations were below the cut-off of 0,30 . Therefore it was decided to proceed with principal factor analysis with a varimax rotation. 
TABLE 2

Factor loadings, COMmUnalities $\left(\mathrm{H}^{2}\right)$, PeRCentage Variance AND COVARIANCE FOR PRINCIPAL FACTORS EXTRACTION AND VARIMAX ROTATION ON COPE ITEMS

\begin{tabular}{|c|c|c|c|c|c|}
\hline Item & $\mathrm{F}_{1}$ & $\mathrm{~F}_{2}$ & $\mathrm{~F}_{3}$ & $\mathrm{~F}_{4}$ & $h^{2}$ \\
\hline Make a plan of action & 0,67 & 0,00 & 0,00 & 0,00 & 0,50 \\
\hline $\begin{array}{l}\text { Concentrate efforts on doing } \\
\text { something about it }\end{array}$ & 0,66 & 0,00 & 0,00 & 0,00 & 0,51 \\
\hline Come up with a strategy & 0,65 & 0,00 & 0,00 & 0,00 & 0,53 \\
\hline Do what has to be done & 0,65 & 0,00 & 0,00 & 0,00 & 0,48 \\
\hline Accept the reality of the fact & 0,65 & 0,00 & 0,00 & 0,00 & 0,44 \\
\hline Think about steps to take & 0,64 & 0,00 & 0,00 & 0,00 & 0,46 \\
\hline Learn from experience & 0,62 & 0,00 & 0,00 & 0,00 & 0,46 \\
\hline Think about best way to handle & 0,61 & 0,00 & 0,00 & 0,00 & 0,46 \\
\hline Prevent other things from interfering & 0,60 & 0,00 & 0,00 & 0,00 & 0,42 \\
\hline Not act too soon & 0,58 & 0,00 & 0,00 & 0,00 & 0,37 \\
\hline Look for something good & 0,55 & 0,00 & 0,00 & 0,00 & 0,36 \\
\hline Take direct action & 0,54 & 0,00 & 0,00 & 0,00 & 0,34 \\
\hline Keep self from getting distracted & 0,53 & 0,00 & 0,00 & 0,00 & 0,37 \\
\hline Try to make it more positive & 0,53 & 0,00 & 0,00 & 0,00 & 0,35 \\
\hline Restrain self from action & 0,52 & 0,00 & 0,00 & 0,00 & 0,34 \\
\hline Grow as a person & 0,52 & 0,00 & 0,00 & 0,00 & 0,32 \\
\hline Take additional action & 0,52 & 0,00 & 0,00 & 0,00 & 0,32 \\
\hline Learn to live with it & 0,50 & 0,00 & 0,00 & 0,00 & 0,27 \\
\hline Get used to the idea & 0,48 & 0,00 & 0,00 & 0,00 & 0,26 \\
\hline Accept that it has happened & 0,48 & 0,00 & 0,00 & 0,00 & 0,28 \\
\hline Give up attempt & 0,00 & 0,65 & 0,00 & 0,00 & 0,43 \\
\hline Give up & 0,00 & 0,64 & 0,00 & 0,00 & 0,42 \\
\hline Pretend it hasn't happened & 0,00 & 0,64 & 0,00 & 0,00 & 0,41 \\
\hline Daydream & 0,00 & 0,60 & 0,00 & 0,00 & 0,39 \\
\hline Act as if it hasn't happened & 0,00 & 0,60 & 0,00 & 0,00 & 0,40 \\
\hline Express emotional distress & 0,00 & 0,56 & 0,00 & 0,00 & 0,35 \\
\hline Say: this isn't real & 0,00 & 0,55 & 0,00 & 0,00 & 0,35 \\
\hline Reduce effort to solve problem & 0,00 & 0,55 & 0,00 & 0,00 & 0,34 \\
\hline Quit trying & 0,00 & 0,54 & 0,00 & 0,00 & 0,31 \\
\hline Refuse to believe it has happened & 0,00 & 0,54 & 0,00 & 0,00 & 0,30 \\
\hline Get upset & 0,00 & 0,53 & 0,00 & 0,00 & 0,32 \\
\hline Let out emotions & 0,00 & 0,51 & 0,00 & 0,00 & 0,31 \\
\hline Drink alcohol or use drugs & 0,00 & 0,51 & 0,00 & 0,00 & 0,29 \\
\hline Discuss feelings with someone & 0,00 & 0,00 & 0,67 & 0,00 & 0,62 \\
\hline Talk to someone about feelings & 0,00 & 0,00 & 0,64 & 0,00 & 0,52 \\
\hline $\begin{array}{l}\text { Get emotional support from } \\
\text { friends/relatives }\end{array}$ & 0,00 & 0,00 & 0,64 & 0,00 & 0,51 \\
\hline $\begin{array}{l}\text { Sympathy and understanding } \\
\text { from someone }\end{array}$ & 0,00 & 0,00 & 0,48 & 0,00 & 0,43 \\
\hline Seek God's help & 0,00 & 0,00 & 0,00 & 0,74 & 0,66 \\
\hline Find comfort in religion & 0,00 & 0,00 & 0,00 & 0,70 & 0,62 \\
\hline Pray more than usual & 0,00 & 0,00 & 0,00 & 0,63 & 0,51 \\
\hline Put trust in God & 0,00 & 0,00 & 0,00 & 0,48 & 0,42 \\
\hline Squared Multiple Correlations & 0,89 & 0,88 & 0,78 & 0,78 & \\
\hline Percentage variance & 17,66 & 10,51 & 6,51 & 4,40 & \\
\hline Percentage covariance & 45,19 & 26,90 & 16,65 & 11,25 & \\
\hline
\end{tabular}

a: Factor labels $\mathrm{F}_{1}$ : Approach Coping $\mathrm{F}_{2}$ : Avoidance $\mathrm{F}_{3}$ : Seeking Emotional Support $\mathrm{F}_{4}$ : Turning to Religion

Inspection of Table 2 shows that four factors were extracted, accounting for $43,29 \%$ of the total variance in the data. As indicated by the SMC's, all factors were internally consistent and well defined by the variables. Variables were reasonably well defined by this factor solution. Communality values, as seen in Table 2, tend to be moderate. With a cut-off of 0,45 for inclusion of a variable in interpretation of a factor, 9 of 53 items did not load on the four factors, while another 3 were discarded due to significant secondary factor loadings.

The first factor dealt with approaching the problem, redefining it as something positive or a learning experience, and accepting that it has happened. Hence, this factor was labelled Approach Coping. The second factor had items that related to avoidance, such as daydreaming, and items related to ignoring the fact. This factor was labelled Avoidance. The third factor was made up by the four items measuring Seeking Social Support for Emotional Reasons (Carver et al., 1989), and was labelled Seeking Emotional Support. The Turning to Religion (Carver et al., 1989) items made up the fourth factor.

The items that failed to load on the four factors included focusing on dealing with the problem, holding off action till the situation permits, waiting for the right time to act, putting aside other activities, taking one's mind off things, sleeping more than usual, venting feelings and seeking advice from other people who have had similar experiences. The items that showed secondary loadings were all items that measure Seeking Social Support for Instrumental Reasons, and all these items loaded on the Approach Coping as well as Seeking Emotional Support factors. The highest loadings were shown for the Seeking Emotional Support factor, but loadings on Approach Coping were also significant. These items were removed from subsequent analyses, and were: getting advice from someone, talking to someone to find out more about the situation, and talking to someone who could do something concrete about the problem.

Table 3 shows the descriptive statistics, alpha coefficients and mean inter-item correlation coefficients for the extracted COPE factors.

TABle 3

DESCRIPTIVE STATISTICS, ALPHA COEFFICIENTS AND MEAN INTERITEM CORRELATION COEFFICIENTS OF THE COPE FACTORS

\begin{tabular}{lcccccccc}
\hline Factor & Mean & $\begin{array}{c}\text { SD Weighted Skewness } \\
\text { Mean }\end{array}$ & Kurtosis & r-Mean & $\alpha$ \\
\hline $\begin{array}{l}\text { Approach Coping } \\
(20 \text { items })\end{array}$ & 59,06 & 12,01 & 2,95 & $-0,82$ & 0,84 & 0,37 & 0,92 \\
Avoidance (13 items) & 27,25 & 8,18 & 2,10 & 0,47 & $-0,26$ & 0,32 & 0,86 \\
$\begin{array}{l}\text { Seeking Emotional } \\
\text { Support (4 items) }\end{array}$ & 10,83 & 3,36 & 3,22 & $-0,35$ & $-0,74$ & 0,50 & 0,80 \\
$\begin{array}{l}\text { Turning to Religion } \\
(4 \text { items })\end{array}$ & 12,60 & 3,13 & 4,02 & 0,92 & 0,20 & 0,55 & 0,83 \\
\hline
\end{tabular}

Table 3 shows that the scores on the COPE are relatively normally distributed. The alpha coefficients of the COPE factors are acceptable compared to the guideline of $\alpha>0,70$ (Nunnally \& Bernstein, 1994). The mean inter-item correlation coefficients are within the range of 0, $15-0,50$ proposed by Clark and Watson (1995), and thus indicate the internal consistency of the factors of the COPE.

Next, exploratory factor analysis and target (Procrustean) rotation were used to determine construct equivalence of the COPE. The factor loadings of race groups were rotated to one target group. After target rotation had been carried out, factorial agreement was estimated using Tucker's coefficient of agreement (Tucker's phi). The Tucker's phi-coefficients for the four race groups are given in Table 4 .

TABLE 4

CONSTRUCT EQUIVALENCE OF THE COPE FOR DIFFERENT RACE GROUPS

\begin{tabular}{lccccc}
\hline Group & $\begin{array}{c}\text { Percentage } \\
\text { of sample }\end{array}$ & $\begin{array}{c}\text { Tucker's } \\
\text { phi }- \\
\text { Approach } \\
\text { Coping }\end{array}$ & $\begin{array}{c}\text { Tucker's } \\
\text { phi }- \\
\text { Avoidance }\end{array}$ & $\begin{array}{c}\text { Tucker's } \\
\text { phi }- \\
\text { Seeking } \\
\text { Emotional } \\
\text { Support }\end{array}$ & $\begin{array}{c}\text { Tucker's } \\
\text { phi }- \\
\text { Turning to } \\
\text { Religion }\end{array}$ \\
\hline White & 41,15 & 0,99 & 0,99 & 0,99 & 0,99 \\
Black & 40,07 & 0,99 & 0,99 & 0,99 & 0,99 \\
Coloured & 14,77 & 0,99 & 0,99 & 0,99 & 0,99 \\
Indian & 4,01 & 0,97 & 0,99 & 0,99 & 0,98 \\
\hline
\end{tabular}


Inspection of Table 4 shows that the Tucker's phi coefficients for White, Black, Coloured and Indian police members were all acceptable $(>0,95)$. Therefore, it can be deduced that the four factors of the COPE were equivalent for the four race groups.

The results of the item bias analyses that were carried out through analysis of variance for the 41 items of the COPE are reported in Table 5.

TABLE 5

ITEM BIAS ANALYSES OF THE COPE

\begin{tabular}{lllllllll}
\hline Item Tot_Ss & Df_g & SS_g & F_g & $\begin{array}{c}\text { Eta } \\
\text { square }\end{array}$ & Df_i & SS_i & F_i & $\begin{array}{c}\text { Eta } \\
\text { square }\end{array}$ \\
\hline
\end{tabular}

Approach Coping

$\begin{array}{lccccccccc}20 & 869,40 & 3 & 0,80 & 0,70 & 0,00 & 27 & 20,10 & 1,70 & 0,02 \\ 45 & 792,50 & 3 & 2,30 & 2,00 & 0,00 & 27 & 19,80 & 1,90 & 0,03 \\ 35 & 803,00 & 3 & 1,40 & 1,20 & 0,00 & 27 & 15,20 & 1,40 & 0,02 \\ 23 & 871,90 & 3 & 2,30 & 1,80 & 0,00 & 27 & 24,20 & 2,10 & 0,03 \\ 48 & 922,10 & 3 & 9,60 & 6,60 & 0,01 & 27 & 18,90 & 1,40 & 0,02 \\ 47 & 888,40 & 3 & 4,80 & 3,40 & 0,01 & 27 & 12,30 & 1,00 & 0,01 \\ 43 & 830,90 & 3 & 0,90 & 0,70 & 0,00 & 27 & 15,00 & 1,30 & 0,02 \\ 9 & 930,80 & 3 & 1,80 & 1,20 & 0,00 & 27 & 13,90 & 1,10 & 0,02 \\ 19 & 998,90 & 3 & 23,20 & 15,40 & 0,02 & 27 & 22,40 & 1,70 & 0,02 \\ 18 & 1104,40 & 3 & 9,90 & 5,40 & 0,01 & 27 & 19,10 & 1,20 & 0,02 \\ 30 & 1022,00 & 3 & 6,30 & 3,70 & 0,01 & 27 & 17,00 & 1,10 & 0,02 \\ 32 & 1064,40 & 3 & 1,90 & 1,00 & 0,00 & 27 & 21,80 & 1,40 & 0,02 \\ 46 & 1010,90 & 3 & 3,50 & 2,00 & 0,00 & 27 & 16,10 & 1,00 & 0,02 \\ 17 & 990,90 & 3 & 0,50 & 0,30 & 0,00 & 27 & 16,30 & 1,10 & 0,02 \\ 31 & 1066,30 & 3 & 4,50 & 2,50 & 0,00 & 27 & 21,80 & 1,30 & 0,02 \\ 3 & 1091,90 & 3 & 19,90 & 10,70 & 0,02 & 27 & 21,30 & 1,30 & 0,02 \\ 6 & 1112,90 & 3 & 1,50 & 0,80 & 0,00 & 27 & 29,20 & 1,60 & 0,03 \\ 21 & 1243,20 & 3 & 32,70 & 15,20 & 0,03 & 27 & 21,70 & 1,10 & 0,02 \\ 7 & 1152,50 & 3 & 6,20 & 2,90 & 0,01 & 27 & 21,10 & 1,10 & 0,02 \\ 33 & 1267,00 & 3 & 6,90 & 3,00 & 0,01 & 27 & 19,40 & 0,90 & 0,02\end{array}$

\section{Avoidance}

$\begin{array}{lccccccccc}26 & 1105,40 & 3 & 3,00 & 1,70 & 0,00 & 27 & 18,90 & 1,20 & 0,02 \\ 50 & 1210,40 & 3 & 5,20 & 2,70 & 0,00 & 27 & 16,50 & 1,00 & 0,01 \\ 29 & 1107,00 & 3 & 0,90 & 0,50 & 0,00 & 27 & 17,10 & 1,10 & 0,02 \\ 52 & 1173,80 & 3 & 1,00 & 0,50 & 0,00 & 27 & 12,30 & 0,70 & 0,01 \\ 42 & 1194,80 & 3 & 13,10 & 6,90 & 0,01 & 27 & 18,90 & 1,10 & 0,02 \\ 40 & 1127,70 & 3 & 2,70 & 1,50 & 0,00 & 27 & 18,70 & 1,10 & 0,02 \\ 16 & 1140,10 & 3 & 38,00 & 20,60 & 0,03 & 27 & 27,50 & 1,70 & 0,02 \\ 39 & 1085,30 & 3 & 5,40 & 2,90 & 0,01 & 27 & 28,80 & 1,70 & 0,03 \\ 13 & 1183,10 & 3 & 4,20 & 2,10 & 0,00 & 27 & 18,90 & 1,00 & 0,02 \\ 2 & 1014,10 & 3 & 1,60 & 0,90 & 0,00 & 27 & 14,80 & 0,90 & 0,02 \\ 53 & 1209,50 & 3 & 35,40 & 18,70 & 0,03 & 27 & 26,90 & 1,60 & 0,02 \\ 27 & 1232,30 & 3 & 36,60 & 18,00 & 0,03 & 27 & 32,50 & 1,80 & 0,03 \\ 12 & 1114,80 & 3 & 25,60 & 14,10 & 0,02 & 27 & 31,10 & 1,90 & 0,03\end{array}$

Seeking Emotional Support

$\begin{array}{lcllllllll}49 & 921,80 & 3 & 1,90 & 1,90 & 0,00 & 27 & 10,10 & 1,10 & 0,01 \\ 8 & 1016,60 & 3 & 4,10 & 3,20 & 0,00 & 27 & 24,20 & 2,10 & 0,02 \\ 15 & 1009,40 & 3 & 6,00 & 4,70 & 0,01 & 27 & 11,20 & 1,00 & 0,01 \\ 28 & 980,60 & 3 & 6,10 & 4,60 & 0,01 & 27 & 28,90 & 2,40 & 0,03\end{array}$

\section{Turning to Religion}

\begin{tabular}{lccccccccc}
51 & 724,00 & 3 & 1,50 & 2,00 & 0,00 & 24 & 6,30 & 1,10 & 0,01 \\
37 & 785,40 & 3 & 3,90 & 4,40 & 0,01 & 24 & 6,30 & 0,90 & 0,01 \\
24 & 794,20 & 3 & 2,40 & 2,50 & 0,00 & 24 & 11,20 & 1,50 & 0,01 \\
10 & 608,30 & 3 & 0,30 & 0,30 & 0,00 & 24 & 6,10 & 0,80 & 0,01 \\
\hline
\end{tabular}

Table 5 shows no significant eta square values for the COPE items. Therefore, it seems that the means of the race groups for the different score levels do not differ from zero in a systematic way. It is clear that the COPE shows no uniform or non-uniform bias for different race groups in the SAPS.

Next, the coping strategies of various demographic groups were investigated. Table 6 shows the differences in COPE factors for different race groups in the SAPS.

TABLE 6

DIFFERENCES IN COPE FACTORS FOR RACES

\begin{tabular}{lccccc}
\hline Factor & White (W) & Black (B) & Coloured (C) & Indian (I) & $\boldsymbol{p}$ \\
\hline Approach Coping & 58,80 & 60,11 & 58,25 & 56,88 & 0,06 \\
Avoidance & $25,18^{\mathrm{B}, \mathrm{b}}$ & $29,48^{\mathrm{a}}$ & $26,99^{\mathrm{B}}$ & $27,79^{\mathrm{B}}$ & $0,00^{*}$ \\
$\begin{array}{l}\text { Seeking Emotional } \\
\text { Support }\end{array}$ & $9,98^{\mathrm{B}, \mathrm{b}}$ & $11,97^{\mathrm{a}}$ & $10,38^{\mathrm{B}}$ & $9,95^{\mathrm{B}, \mathrm{b}}$ & $0,00^{*}$ \\
\begin{tabular}{l} 
Turning to Religion \\
\hline
\end{tabular} & 12,51 & 12,63 & 12,79 & 12,21 & 0,55 \\
\hline
\end{tabular}

* Statistically significant difference $(p<0,05)$. Letter in superscript indicates difference from race group.

a Practically significant difference between races in row where $\mathrm{b}$ (medium effect, $d$ larger or equal to 0,50 ) or c (large effect, $d$ larger or equal to 0,80 ) are indicated

Table 6 shows that statistically significant differences were recorded for Avoidance, with Whites, Coloureds and Indians scoring lower than Blacks. However, only one practically significant effect was found with Whites scoring lower than Blacks on Avoidance (medium effect). Regarding Seeking Emotional Support, Blacks scored higher statistically significantly higher on Seeking Emotional Support than the other three groups. However, only two effects were practically significant (medium effect), namely the differences between Whites and Blacks as well as Indians and Blacks.

Table 7 indicates the differences found for the COPE factors for different ranks.

TABLE 7

DIFFEREBCES IN COPE FACTOR FOR RANKS

\begin{tabular}{lccccccc}
\hline Factor & CST & SRT & INS & CPT & SUP & SNR & $\boldsymbol{p}$ \\
\hline Approach Coping & 59,16 & 57,69 & 58,92 & 60,81 & 60,09 & 64,50 & 0,06 \\
Avoidance & $27,04^{\mathrm{b}}$ & $29,97 \mathrm{c}$ & 26,71 & 26,36 & 25,69 & $21,90^{\mathrm{a}}$ & $0,00^{*}$ \\
$\begin{array}{l}\text { Seeking Emotional } \\
\text { Support }\end{array}$ & 11,14 & 11,14 & 10,74 & 10,70 & 10,00 & 11,00 & 0,28 \\
Turning to Religion & 12,15 & 12,40 & 12,72 & 12,48 & 13,31 & 13,40 & 0,20 \\
\hline
\end{tabular}

$\mathrm{CST}=$ Constable; $\mathrm{SRT}=$ Sergeant; $\mathrm{INS}=$ Inspector; $\mathrm{CPT}=$ Captain; $\mathrm{SUP}=$ Superintendent; $\mathrm{SNR}=$ Senior Superintendent

* Statistically significant $\leq \mathrm{p} £ 0,05)$

a Practically significant difference between ranks in row where $\mathrm{b}$ (medium effect, $d$ larger or equal to 0,50 ) or $c$ (large effect, $d$ larger or equal to 0,80 ) are indicated

Table 7 shows that statistically and practically significant differences exist in the means of constables, sergeants and senior superintendents regarding Avoidance. Senior superintendents obtained lower scores than constables (practically significant, medium effect) and sergeants (practically significant, large effect).

\section{DISCUSSION}

The factor analysis of the COPE items yielded a four-factor solution, namely Approach Coping, Avoidance, Seeking Emotional Support and Turning to Religion. The original proposition by Carver et al. (1989) was also four factors, and the current study bears some resemblance to that. The 
resemblance can be found in the social/emotional, avoidance and approach coping (task- or problem-directed) factors. These factors are also a close resemblance of three identified by Amirkhan (1990). Strong support thus exists for the conclusion of Kallasmaa and Pulver (2000) that a minimum of three factors is needed to explain coping data adequately.

However, direct comparison of the current results with those of Carver et al. (1989) is impossible, because the item loadings on the proposed primary factors were not reported. The first and second factors extracted in this study reflect the known styles of Approach Coping (or alternatively referred to as active coping) and Avoidance. The second factor clearly deals with an avoidant type of approach, including items that refer to giving up, denying the reality of the situation/problem, letting emotions out and using alcohol or drugs to cope. The four items measuring Seeking Social Support for Emotional Reasons (Carver et al., 1989) made up the third factor. Only two other studies reviewed in the literature section of this paper found Seeking Social Support for Instrumental and Seeking Social Support for Emotional Reasons to load on different factors (Bishop et al., 2001; Phelps \& Jarvis, 1994). Items measuring Seeking Social Support for Instrumental Reasons also loaded strongly on the first factor, Approach Coping. This subscale has been associated with active coping in previous research (Lyne \& Roger, 2000), and specifically in the policing context (Bishop et al., 2001). The current findings are in agreement with Bishop et al. (2001) who found that Seeking Social Support for Instrumental Reasons load on the active coping factor for a police sample. These findings suggest that in a policing context, Seeking Social Support for Instrumental Reasons is an active strategy with a problem focus. Turning to Religion items made up the fourth factor, which replicates previous research findings (Lyne \& Roger, 2000; Sica et al., 1997) in showing this subscale to emerge as a fourth factor.

The findings of this study support a proposition originally put forward by Cox and Ferguson (1991) and Ferguson and Cox (1997), that coping dimensions could be classified as problemfocused, emotion-focused, reappraisal and avoidance. The factor identified as Approach Coping in this study probably overlaps with problem-focused coping (and seems to be a cognitive-behaviour coping strategy). It would include active efforts at cognitively and behaviourally dealing with the source of stress. The second factor extracted in this study, namely Avoidance has to do with cognitive and behavioural disengagement and avoidance. Seeking Emotional Support, the third factor extracted in this study is related to the affective dimension of human beings, and dealings with the emotional reactions evoked by the stressful situation. The fourth coping strategy, namely Turning to Religion taps into the religious dimension of police members and may affect their appraisal processes (see Zeidner \& Hammer, 1992). By means of religion, stressors can be made meaningful by reappraising them within a perceptual framework that guides acceptable coping strategies. Unpleasant experiences derive meaning from being "acts of God", and therefore not in need of reasonable explanation.

Alpha coefficients of the COPE factors were acceptable. The factors also showed internal consistency. The factors extracted showed structural equivalence for the four race groups included in this study, as demonstrated by Tucker's phi coefficients. The latter finding is of special importance, since no studies were previously conducted regarding structural equivalence of the COPE for different race groups in South Africa. Although generalisations would be premature, without the extraction of these factors in other occupations, these results indicate that the extracted coping factors are valid across race groups within the SAPS. Furthermore, no evidence was found which proved either uniform or non-uniform bias of the items of the COPE.
An interesting result from the comparison of factor analyses of the COPE was that the factors of Task and Cognitive Coping originally produced have subsequently emerged as a single factor in various studies (Cook \& Heppner, 1997; Ferguson, 2001; Fortune et al., 2002; Ingledew et al., 1996). This combined factor has also been reproduced in other studies, with the extra scales of Seeking Social Support for Instrumental Reasons (Lyne \& Roger, 2000), and Turning to Religion (Laurent et al., 1997). Acceptance, Restraint Coping and Positive Reinterpretation and Growth can thus be thought of as Approach Coping strategies together with Active coping, Planning and Suppression of Competing Activities.

The Seeking Emotional Support factor is rather specific and does not include a wide array of emotion items, but relates specifically to the mobilisation of social support in dealing with experienced emotions. Coping through emotional approach has been suggested to carry adaptive potential (Stanton, Kirk, Cameron \& Danoff-Burg, 2000; Stanton, Parsa \& Austenfeld, 2002). The current factor suggests that individuals rather approach than avoid their emotional reactions (see Stanton et al., 2002), by means of eliciting social support. Although research on emotional approach coping suggests that coping through actively processing and expressing emotion can confer psychological and physical health advantages (Stanton et al., 2000; Stanton et al., 2002), the current research does not elucidate these previous findings.

The emergence of Turning to Religion as a separate factor is of interest. This confirms the finding of Rothmann and Strijdom (2002) and Rothmann and Van Rensburg (2001) that Turning to Religion seems to be an important coping strategy in the SAPS. Since the SAPS employ chaplains as part of their permanent members, it can be understood why this strategy was rated highest in a national sample, if the context that actively endorses religion as coping strategy is taken into account. The question that should however be investigated goes to the function and effectiveness of this coping strategy.

For different race groups, Blacks scored higher on Avoidance than both Whites and Coloured people. Regarding the Seeking of Emotional Support, Blacks measured higher than Whites, Indians and Coloured people. These findings show that Black members of the SAPS are more inclined to seek emotional support, and have a more avoidant coping strategy.

Senior superintendents were shown to score lower on Avoidance than both constables and sergeants. This effect might be explained by the nature of the work these different ranks have to perform. While the senior superintendent is often the station manager, and thus in charge of a wider array of functions, the constable and sergeant can be considered front-line, and more exposed to hands-on police work. Feelings of ineffectiveness and frustrated goals on the side of constables and sergeants could account for more avoidant coping.

\section{RECOMMENDATIONS}

It is recommended that the COPE be factor-analysed at the item level in subsequent research, because of the variations found for subscale analyses. Especially with regard to cross- and intercultural comparisons, this seems a valid recommendation. The variability of subscales in previous research in loading on secondary factors acts only to complicate interpretation.

The content of items should guide future researchers in distinguishing coping strategies. It would also be strongly recommended that a standardised measure be made generally available, so that future studies can make use of the same version of the questionnaire. This is an ideal solution, because the utility of the subscales originally proposed by Carver et al. (1989) can only really be determined with the comparison of 
equivalent versions of the questionnaire in future. It is proposed that future research should look for four factors in coping, namely an active, avoidant/passive, social/emotional and a religion and/or humour factor.

Following other researchers (Kowalski \& Crocker, 2001), it is also recommended here that studying the functions and effectiveness of coping strategies would facilitate a more complete understanding of coping. In the SAPS this is of special relevance to Turning to Religion, since it is a coping strategy actively endorsed by the organisation. The use of a combination of both qualitative and quantitative techniques to better understand this coping process is suggested (Cooper, Dewe \& $\mathrm{O}^{\prime}$ Driscoll, 2001).

The Seeking Emotional Support factor could be elaborated by making use of the emotion approach coping scales as proposed by Stanton et al. (2000). It would be interesting to see if police officers prefer emotional expression or emotional processing, since emotional expression is not encouraged in a policing environment (Kop \& Euwema, 2001; Stephens \& Long, 2000).

Future studies of police coping should be done in conjunction with personality measures, to clarify the relationship between personality variables and coping dispositions. Since coping has also been related to strain outcomes, such as burnout, job dissatisfaction, physical complaints and intention to quit (Anderson, 2000; De Rijk, Le Blanc, Schaufeli \& De Jonge, 1998; Koeske, Kirk \& Koeske, 1993; Parkes, 1990) studying the relationship between coping and job stress and strain in the SAPS is also recommended.

\section{REFERENCES}

Amirkhan, J.H. (1990). A factor analytically derived measure of coping: The Coping Strategy Indicator. Journal of Personality and Social Psychology, 59, 1066-1074.

Anderson, D. G. (2000). Coping strategies and burnout among veteran child protection workers. Child Abuse and Neglect, 24, 849-859.

Anshel, M.H. (2000). A conceptual model and implications for coping with stressful events in police work. Criminal Justice and Behavior, 27, 375-400.

Ball, R., Warheit, G., Vandiver, J. \& Holzer, C. (1980). Friendship networks: More supportive of low-income Black women? Ethnicity, 7, 70-77.

Ben-Zur, H. (1998) (in Hebrew). Strategies of coping with stress: The adaptation of the complete Hebrew version of the COPE inventory (working paper). In H. Ben-Zur (Ed.), The effectiveness of coping meta-strategies: Perceived efficiency, emotional correlates and cognitive performance. Personality and Individual Differences, 26, 923-939.

Ben-Zur, H. (1999). The effectiveness of coping meta-strategies: Perceived efficiency, emotional correlates and cognitive performance. Personality and Individual Differences, 26, 923-939.

Bhagat, R.S., Ford, D.L., O' Driscoll, M.P., Frey, L., Babakus, E. \& Mahanyele, M. (2001). Do South African managers cope differently from American managers? A cross-cultural investigation. International Journal of Intercultural Relations, $25,301-313$

Billings, A.G. \& Moos, R.H. (1984). Coping, stress and social resources among adults with unibipolar depression. Journal of Personality and Social Psychology, 46, 877-891.

Bishop, G.D., Tong, E.M.W., Diong, S.M., Enkelmann, H.C., Why, Y.P., Khader, M. \& Ang, C.H. (2001). The relationship between coping and personality among police officers in Singapore. Journal of Research in Personality, 35, 353-374.

Burke, R.J. (1993). Work-family stress, conflict, coping and burnout in police officers. Stress Medicine, 9, 171-80.

Burke, R.J. \& Deszca, E. (1986). Correlates of psychological burnout phases among police officers. Human Relations, 39, 487-502.
Carver, C.S., Scheier, M.F. \& Weintraub, J.K. (1989). Assessing coping strategies: A theoretically based approach. Journal of Personality and Social Psychology, 56, 267-283.

Clark, L.A. \& Watson, D. (1995). Construct validity: Basic issues in objective scale development. Psychological Assessment, 7, 309-319.

Cleary, T.A. \& Hilton, T.L. (1968). An investigation of item bias. Educational and Psychological Measurement, 28, 61-75.

Cohen, J. (1988). Statistical power analysis for the behavioral sciences ( $2^{\text {nd }}$ ed.). Hillsdale, NJ: Lawrence Erlbaum \& Associates

Cohen, R. \& Lazarus, R.S. (1979). Coping with stresses of illness. In G.C. Stone, F. Cohen, \& N.F. Adler (Eds.), Health psychology. San Francisco: Jossey-Bass.

Cook, S.W. \& Heppner, P.P. (1997). A psychometric study of three coping measures. Educational and Psychological Measurement, 57, 906-923.

Cooper, C.L., Dewe, P.J. \& O'Driscoll, M.P. (2001). Organizational stress: A review and critique of theory, research, and applications. London: Sage Publications.

Cox, T. \& Ferguson, E. (1992). Individual differences, stress and coping. In C.L. Cooper \& R. Payne (Eds.), Personality and stress: Individual differences in the stress process. Chichester, UK: Wiley.

Coyne, J.C. \& Downey, G. (1991). Social factors and psychopathology: Stress, social support and coping processes. Annual Review of Psychology, 42, 401-425.

Coyne, J.C. \& Gottlieb, B.H. (1996). The mismeasurement of coping by checklist. Journal of Personality, 64, 959-991

De Rijk, A. E., Le Blanc, P. M., Schaufeli, W. B. \& De Jonge, J. (1998). Active coping and need for control as moderators of the job demand-control model: Effects on burnout. Journal of Occupational and Organizational Psychology, 71, 1-18.

Dietrich, J. \& Smith, J. (1984). The nonmedical use of drugs including alcohol among police personnel: A critical literature review. Journal of Police Science and Administration, 14, 300-306.

Endler, N.S. \& Parker, J.D.A. (1990). Coping Inventory for Stressful Situations (CISS): Manual. Toronto: Multi-Health Systems.

Evans, B.J. \& Coman, G.J. (1992). General versus specific measures of occupational stress: An Australian police survey. Stress Medicine, 9, 11-20.

Evans, B.J., Coman, G., Stanley, R.O. \& Burrows, G.D. (1993) Police officers' coping strategies: An Australian police survey. Stress Medicine, 9, 237-246.

Fain, D.B. \& McCormick, G.M. (1988). Use of coping mechanisms as a means of stress reduction in North Louisiana. Journal of Police Science and Administration, 16, 21-28.

Ferguson, E. (2001). Personality and coping traits: A joint factor analysis. British Journal of Health Psychology, 6, 311-325.

Ferguson, E. \& Cox, T. (1997). The Functional Dimensions of Coping Scale: Theory reliability and validity. British Journal of Health Psychology, 2, 109-129.

Finch, J.F., Panter, A.T. \& Caskie, G.I.L. (1999). Two approaches for identifying shared personality dimensions across methods. Journal of Personality, 67, 407-438.

Folkman, S. \& Lazarus, R.S. (1980). An analysis of coping in a middle-aged community sample. Journal of Health and Social Behavior, 21, 219-239.

Folkman, S., Lazarus, R.S., Pimley, S. \& Novacek, J. (1987). Age differences in stress and coping processes. Psychology and Aging, 2, 171-184.

Fortune, D.G., Richards, H.L., Griffiths, C.E.M. \& Main, C.J. (2002). Psychological stress, distress and disability with psoriasis: Consensus and variation in the contribution of illness perceptions, coping and alexithymia. British Journal of Clinical Psychology, 41, 157-174.

Friedman, H.S. \& Vandenbos, G.R. (1992). Disease-prone and self-healing personalities. Hospital and Community Psychiatry, 43, 1177-1179.

Greenglass, E.R. (1996). Anger suppression, cynical distrust, and hostility: Implications for coronary heart disease. In J.M.T. Brebner, E. Greenglass, P. Laungani \& A.M. O’Roark (Eds.), Stress and emotion. Volume 16. Washington, DC: Taylor \& Francis. 
Hardy, L., Jones, G. \& Gould, D. (1996). Understanding psychological preparation for sport: Theory and practice of elite performers. Chichester, UK: Wiley.

Hart, P.M., Wearing, A.J. \& Headey, B. (1995). Police stress and well-being: Integrating personality, coping and daily work experiences. Journal of Occupational and Organizational Psychology, 68, 133-156.

Headey, B. \& Wearing, A.J. (1990). Subjective well-being and coping with adversity. Social Indicators Research, 22, 327-349.

Hudec-Kneeviæ, J. \& Kardum, I. (1996). A model of coping with conflicts between occupational and family roles: Structural analysis. Personality and Individual Differences, 21, 355-372.

Hudec-Kneeviæ, J., Kardum, I. \& Vukmiroviæ, Z. (1999). The structure of coping styles: A comparatively study of a Croatian sample. European Journal of Personality, 13, 149-161.

Hui, C.H. \& Triandis, H.C. (1985). Measurement in crosscultural psychology. Journal of Cross-Cultural Psychology, 16, 131-152.

Hurrel, J.J. (1995). Police work, occupational stress and individual coping. Journal of Organizational Behavior, 16, 27-28.

Ingledew, D.K., Hardy, L., Cooper, C.L. \& Jemal, H. (1996). Health behaviours reported as coping strategies: A factor analytical study. British Journal of Health Psychology, 1, 263-281.

Kallasmaa, T. \& Pulver, A. (2000). The structure and properties of the Estonian COPE inventory. Personality and Individual Differences, 29, 881-894.

Kardum, I. \& Kneeviæ, J. (1995). The relationship between Eysenck's personality traits, coping styles and moods. Personality and Individual Differences, 20, 341-350.

Kerlinger, F.N. \& Lee, H. B. (2000). Foundations of behavioral research (4th ed.). London: Harcourt College Publishers.

Kessler, R.C., Price, R.H. \& Wortman, C.B. (1985). Social factors in psychopathology: stress, social support, and coping processes. Annual Review of Psychology, 36, 531-572.

Knight, G.P. \& Hill, N. (1998). Measurement equivalence in research involving minority adolescents. In V. McLoyd \& L. Steinberg (Eds.), Research on minority adolescents: Conceptual, methodological and theoretical issues. Hillsdale, NJ: Erlbaum.

Koeske, G. F., Kirk, S. A. \& Koeske, R. D. (1993). Coping with job stress: Which strategies wok best? Journal of Occupational and Organizational Psychology, 66, 319-335.

Kop, N. \& Euwema, M. C. (2001). Occupational stress and the use of force by Dutch police officers. Criminal Justice and Behavior, 28, 631-652.

Kowalski, K.C. \& Crocker, P.R.E. (2001). Development and validation of the Coping Function Questionnaire for adolescents in sport. Journal of Sport and Exercise Psychology, 23, 136-155.

Laurent, J., Catanzaro, S.J. \& Callan, M.K. (1997). Stress, alcoholrelated experiences and coping preferences: A replication with adolescents of the Cooper et al. (1992) model. Journal of Studies on Alcohol, 58, 644-651.

Lazarus, R.S. \& Folkman, S. (1984). Stress, appraisal, and coping. New York: Springer.

Livneh, H., Antonak, R.F. \& Gerhardt, J. (2000). Multidimensional investigation of the structure of coping among people with amputations. Psychosomatics, 41, 235244.

Lyne, K. \& Roger, D. (2000). A psychometric re-assessment of the COPE questionnaire. Personality and Individual Differences, 29, 321-335.

Malloy, T.E. \& Mays, L. (1984). The police stress hypothesis: A critical evaluation. Criminal Justice and Behavior, 11, 197-224.

Mitchell, G. \& Hastings, R.P. (2001). Coping, burnout, and emotion in staff working in community services for people with challenging behaviors. American Journal on Mental Retardation, 106, 448-459.

Nedcor Project on Crime, Violence and Investment: 1996, Final Report. (The Nedcor Project, Johannesburg).
Nel, J. (1994). A contextual approach to post-shooting trauma in the South African Police Service. Unpublished master's dissertation, Rand Afrikaans University, Johannesburg.

Nel, J. \& Burgers, T. (1998). Stress and trauma in the work environment: The South African Police Service. Unisa Psychologia, 25 (2), 17-25

Nezu, A.M. \& Carnevale, G.J. (1987). Interpersonal problem solving and coping reactions of Vietnam veterans with posttraumatic stress disorder. Journal of Abnormal Psychology, 96, $155-157$

Nordlicht, S. (1979). Effects of stress on the police officer and family. New York State Journal of Medicine, 79, 400-401.

Nunnally, J. \& Bernstein, I.H. (1994). Psychometric theory (3 ${ }^{\text {rd }}$ ed.). New York: McGraw-Hill.

Parker, J.D.A. \& Endler, N.S. (1992). Coping with coping assessment: A critical review. European Journal of Personality, 6, 321-344.

Parkes, K. R. (1990). Coping, negative affectivity and the work environment: Additive and interactive predictors of mental health. Journal of Applied Psychology, 75, 399-409.

Patterson, G.T. (1999). Coping effectiveness and occupational stress in police officers. In Violanti, J.M. \& Paton, D. (Eds). Police trauma: Psychological aftermath of civilian combat. Springfield, IL: C.C. Thomas

Phelps, S.B. \& Jarvis, P.A. (1994). Coping in adolescence: Empirical evidence for a theoretically based approach to coping. Journal of Youth and Adolescence, 23, 359-371.

Prelow, H.M., Tein, J.Y., Roosa, M.W. \& Wood, J. (2000). Do coping styles differ across sociocultural groups? The role of measurement equivalence in making this judgement. American Journal of Community Psychology, 28, 225-244.

Pretorius, C. (1998, March 2). Police hit by stress, suicides. The Citizen, 1.

Rothmann, S. \& Agathagelou, A.M. (2000). Die verband tussen lokus van beheer en werkstevredenheid by senior polisiepersoneel. Tydskrif vir Bedryfsielkunde, 26, 20-26.

Rothmann, S., Sieberhagen, G. \& Cilliers, F.V.N. (1998). Die kwalitatiewe effek van ' $\mathrm{n}$ groepfasiliteringskursus. Tydskrif vir Bedryfsielkunde, 24 (3), 7-13.

Rothmann, S. \& Strijdom, G. (2002). Suicide ideation in the South African Police Service in the North West Province. South African Journal of Industrial Psychology, 28, 44-48.

Rothmann, S. \& Van Rensburg, P. (2001, May). Suicide ideation in the South African Police Service. Paper presented at the 10th European Congress on Work and Organizational Psychology, Prague, Czech Republic.

SAS Institute. (2000). The SAS System for Windows Release 8. Cary, NC: SAS Institute Inc.

Schwarzer, R. \& Schwarzer, C. (1996). A critical survey of coping instruments. In M. Zeidner \& N.S. Endler (Eds.), Handbook of coping: Theory, research, applications. New York: Wiley.

Shaughnessy, J.J. \& Zechmeister, E.B. (1997). Research methods in psychology (4th ed.). New York: McGraw-Hill.

Sica, C., Novara, C., Dorz, S. \& Sanavio, E. (1997). Coping strategies: Evidence for cross-cultural differences? A preliminary study with the Italian version of Coping Orientations to Problems Experienced (COPE). Personality and Individual Differences, 23, 1025-1029.

Slavin, L.A., Rainer, K.L., McCreary, M.L. \& Gowda, K.K. (1991). Toward a multicultural model of stress process. Journal of Counselling and Development, 70, 156-163).

Solomon, Z., Avitzur, M., \& Mikulincer, M. (1989). Coping resources and social functioning following combat stress reactions: A longitudinal study. Journal of Social and Clinical Psychology, 8, 87-96.

Solomon, Z., Mikulincer, M. \& Avitzur, M. (1988). Coping, locus of control, social support and combat-related post-traumatic stress disorder. Journal of Personality and Social Psychology, 55, 279-285.

Stanton, A.L., Kirk, S.B., Cameron, C.L. \& Danoff-Burg, S. (2000). Coping through emotional approach: Scale construction and 
validation. Journal of Personality and Social Psychology, 78, 1150-1169.

Stanton, A. L., Parsa, A. \& Austenfeld, J. L. (2002). The adaptive potential of coping through emotional approach. In C.R. Snyder \& S.J. Lopez (Eds.), Handbook of positive psychology. New York: Oxford University Press.

Stephens, C. \& Long, N. (2000). Communication with police supervisors and peers as a buffer to work-related traumatic stress. Journal of Organizational Behavior, 21, 407-424

Steyn, H.S. (1999). Praktiese betekenisvolheid. Die gebruik van effekgroottes. Wetenskaplike bydraes - reeks B: Natuurwetenskappe Nr. 117. Potchefstroom: PU vir CHO.

Storm, K. \& Rothmann, S. (in press). The relationship between burnout, personality traits and coping strategies in a corporate pharmaceutical group. South African Journal of Industrial Psychology.

Terry, D.J., Callan, V.J. \& Sartori, G. (1996). Employee adjustment to an organizational merger: Stress, coping and inter-group differences. Stress Medicine, 12, 105-122.
Terry, D.J., Tonge, L. \& Callan, V.J. (1995). Employee adjustment to stress: The role of personal resources, situational factors, and coping strategies. Anxiety, Stress, and Coping, 8, 1-24.

Van de Vijver, F.J.R. \& Leung, K. (1997). Method and data analysis for cross-cultural research. Beverly Hills, CA: Sage.

Violanti, J.M. (1992). Coping strategies among police recruits in a high-stress training environment. The Journal of Social Psychology, 132, 717-729.

Violanti, J.M. \& Paton, D. (1999). Police trauma: Psychological aftermath of civilian combat. Springfield, IL: C.C. Thomas.

Ward, C. \& Kennedy, A. (2001). Coping with cross-cultural transition. Journal of Cross-Cultural Psychology, 32, 636-642.

Zeidner, M. \& Ben-Zur, H. (1994). Individual differences in anxiety, coping, and post-traumatic stress in the aftermath of the Persian Gulf War. Personality and Individual Differences, 16, 459-476.

Zeidner, M. \& Hammer, A.L. (1992). Coping with missile attack: Resources, strategies, and outcomes. Journal of Personality, 60, 709-746. 